\title{
Low Vitamin D Deficiency Associated With Thyroid Disease Among Type 2 Diabetic Mellitus Patients
}

\author{
Abdulbari Bener ${ }^{\mathrm{a}, \mathrm{b}}$, c, g, Yasar Ozdenkaya ${ }^{\mathrm{d}}$, Abdulla O.A.A. Al-Hamaq ${ }^{\mathrm{e}}$, \\ Cem Cahit Barisik ${ }^{\mathrm{f}}$, Mustafa Ozturk ${ }^{\mathrm{c}}$
}

\begin{abstract}
Background: The aim of this study was to investigate the relationship between vitamin $\mathrm{D}$ deficiency and thyroid diseases among type 2 diabetes mellitus (T2DM) patients.

Methods: This was a cohort case and control study, 546 T2DM patients and 546 control study participants were enrolled, aged between 25 and 65 years. The subjects were also investigated for fasting blood glucose levels (FBG), post prandial glucose (PPG,) glycosylated hemoglobin (HbA1c), thyroid stimulating hormone (TSH), T3, T4, and presence of other comorbid conditions. Thyroid fine needle aspiration biopsy was suggested to patients whose thyroid nodules were greater than $1.00 \mathrm{~cm}$.
\end{abstract}

Results: There were significant differences between T2DM patients and control subjects regarding BMI $\left(\mathrm{kg} / \mathrm{m}^{2}\right)$, physical activity, cigarette smoking, sheesha smoking, family history of diabetes, hypertension and family history of thyroid nodules. The clinical biochemistry values among T2DM for vitamin $\mathrm{D}$, calcium, magnesium, potassium, phosphorous, fasting blood glucose, cholesterol, HbA1c, HLDL, LDL, triglyceride, systolic blood pressure (SBP) and diastolic blood pressure (DBP) were lower than control subjects, but higher in creatinine, albumin, TSH, T3, and T4 which appeared statistically significant differences $(\mathrm{P}<0.001)$. Also, the study revealed statistically significant differences between subjects vitamin D deficiency and with

Manuscript submitted June 7, 2018, accepted June 18, 2018

aDepartment of Biostatistics and Medical Informatics, Cerrahpasa Faculty of Medicine, Istanbul University, Istanbul, Turkey

${ }^{b}$ Department of Evidence for Population Health Unit, School of Epidemiology and Health Sciences, The university of Manchester, Manchester, UK

'Department. of Endocrinology, Medipol International School of Medicine, Istanbul Medipol University, Istanbul, Turkey

${ }^{\mathrm{d}}$ Qatar Diabetic Associations and Qatar National Research Foundation, Doha, Qatar

eDepartment of Surgery, Medipol School of Medicine, Istanbul Medipol University, Istanbul, Turkey

fDepartment of Radiology and Pathology, Medipol School of Medicine, Istanbul Medipol University, Istanbul, Turkey

${ }^{g}$ Corresponding Author: Abdulbari Bener, Department of Biostatistics and Medical Informatics, Cerrahpaşa Faculty of Medicine, Istanbul University and Istanbul Medipol University, International School of Medicine, 34098 Cerrahpasa, Istanbul, Turkey. Email: abdulbari.bener@istanbul.edu.tr

doi: https://doi.org/10.14740/jocmr3507w thyroid nodules for calcium, magnesium, phosphorous, $\mathrm{HbA1c}$, high density lipoprotein (HDL), SBP and DBP, TSH, T3, and T4 among T2DM patients and control subjects $(\mathrm{P}<0.001)$. Multivariable stepwise logistic regression analysis showed that TSH, HbA1c, vitamin D deficiency, SBP (mm Hg), BMI, family history of DM, serum calcium level and family history of thyroid were considered at higher risk as predictors of thyroid among T2DM patients.

Conclusions: This study suggests that obesity, HbAlc, the environment, and genetic susceptibility among T2DM, may increase the risk of thyroid disease and cancer. Although evidence has shown that thyroid cancer incidence has been rising more rapidly over time than the occurrence of cancers of other sites, due to an increase of obesity, diabetes and lack of physical activity, this study lacks of direct evidence supporting this conclusion.

Keywords: Vitamin D deficiency; Thyroid disease; TSH; HbA1C; T2DM; Prevention

\section{Introduction}

Type 2 diabetes mellitus (T2DM) and thyroid dysfunction are the main threats in developed and developing countries and impairs the health and economic status $[1,2]$. T2DM increases the risk of coronary heart disease $[3,4]$ and thyroid dysfunction [5-9] in the long-term. T2DM and thyroid dysfunction are the primary reasons for mortality and morbidity in most highincome and developing countries [5-9].

Thyroid disorders and diabetes are the two most widespread endocrinological medical conditions seen in general clinical medical practice [4]. Achieving good glycemic control prevents cardiovascular risk associated with diabetes [1-5]. However, several studies have shown a higher prevalence of thyroid dysfunction occurring among T2DM patients, and vice versa [7-12].

Positive correlations between vitamin D deficiency and thyroid dysfunction among T2DM patients have been reported by several authors [11-15]. The impact of vitamin D deficiency on thyroid diseases which are highly correlated as the two most common endocrinological medical conditions was reported in clinical practice [13-15]. We designed the present study to test the hypothesis that lower vitamin D levels may be related to the occurrence of thyroid disease. This study is a cross-sectional case-control analysis in which we examined the levels 
of $25(\mathrm{OH}) \mathrm{D}$ in patients with thyroid among both T2DM and in controls. The aim of this study was to explore the association between vitamin $\mathrm{D}$ deficiency and thyroid dysfunction among T2DM patients.

\section{Materials and Methods}

The design of this study was a case and control. The study involved participants between the ages of 25 and 65 who visited the diabetes, endocrinology, thyroid surgery and outpatient clinics in the Mega Medipol International School of Medicine Hospital and Medipol Hospital from March 2016 to May 2018. This case and control study was based on 546 type 2 diabetic and 546 control subjects. IRB ethical approval for the present study was taken from the Medipol International School of Medicine, Istanbul Medipol University, and patients gave informed written consent before starting.

\section{Laboratory measurements}

Case patients were considered to have DM if they had a history of DM and were currently taking any oral medications for diabetes. According to the World Health Organization (WHO) and the International Diabetes Federation (IDF) [1, 2], the criterion for diagnosing DM is when fasting venous blood glucose $(\mathrm{FBG})$ concentration is equal to or higher than 7.0 $\mathrm{mmol} / \mathrm{L}$ and/or postprandial blood glucose (PPG) concentration is higher than $11.1 \mathrm{mmol} / \mathrm{L}[1,3]$. A subject was included in the control group (subjects without diabetes) if FBG was less than $7.0 \mathrm{mmol} / \mathrm{L}(126 \mathrm{mg} / \mathrm{dL})$ and glycosylated hemoglobin (HbA1c) less than $48 \mathrm{mmol} / \mathrm{mol}(6.5 \%)$ and no prescribed diabetic medications were reported.

These subjects were also investigated for FBG, serum cholesterol, serum triglycerides, high density lipoprotein (HDL), low density lipoprotein (LDL), PPG, HbA1c, very low density lipoprotein (VLDL), blood urea, and serum creatinine.

\section{Blood collection and serum measurements of vitamin D}

The collected venous blood sample, and serum were separated and stored at $-70{ }^{\circ} \mathrm{C}$ until examination. Serum 25 -hydroxyvitamin D (25OHD), a vitamin D metabolite, was measured using a commercially obtainable kit (DiaSorin Corporate Headquarter, Saluggia, Italy). The treated samples were then assayed using the competitive binding radioimmunoassay (RIA) technique. Subjects were classified into two categories as : 1) Vitamin D deficiency, 25(OH)D $<20 \mathrm{ng} / \mathrm{mL}$; 2) Vitamin sufficiency, $25(\mathrm{OH}) \mathrm{D}>20 \mathrm{ng} / \mathrm{mL}$ on the basis of previous recommendations by Bener et al [3] and Mazokopakis and Kotsiris [14] and Holick et al [15].

\section{Thyroid evaluation}

A thyroid nodule is a lump that occurs from the abnormal growth of thyroid cells, located at the base of the neck and produces the hormones thyroxine and triiodothyronine [16-19]. Thyroid functioning was assessed by measuring thyroid stimulating hormone (TSH), free-T3 (FT3), and free-T4 (FT4), using immunochemoluminescent assays by an automated analyzer [20], (Immulite 2000; Diagnostic Products, Los Angeles, CA, USA). A 10-MHz linear probe (Logiq 5 Pro, GE Medical Systems, WI, USA) was used by same physician (CCB) for thyroid ultrasonography. TSH was measured by immunoassay [17]. The measurement of FT3 and FT4 are the most clinically relevant for the evaluation of thyroid disorders, with total thyroid hormones being affected by variations in binding protein concentrations. It is essential that free thyroid hormone measurement accurately assess hormone concentration even in the presence of significant variation Thyroid fine needle aspiration biopsy was suggested to patients whose thyroid nodules were greater than $1.00 \mathrm{~cm}$.

\section{Questionnaire, physical examination and measurements}

This study included several parameters such as socio-demographic characteristics, lifestyle habits and biochemical test results. Patients were categorized as physically active if they walked or cycled for more than 30 min per day.

The data was analyzed using the Statistical Package for the Social Sciences (IBM SPSS Statistics for Windows, Version 22.0.). The significance of differences between mean values of two continuous variables was determined by Student's $t$-test for normally distributed data and by Mann-Whitney test for not normal distribution data. Chi-square and Fisher's exact tests performed for significance differences between two or more categorical groups. Multivariate logistic regression analysis was performed to predict the risk factors for the presence of thyroid nodules. The cut-off value for determining significance was chosen as 0.05 .

\section{Results}

Table 1 presents socio-demographic and clinical characteristics of studied T2DM patients and control subjects. There were statistically significant differences between T2DM patients and control subjects regarding BMI, physical activity, cigarette smoking, sheesha smoking, family history of diabetes, hypertension and family history thyroid nodules.

Table 2 shows the clinical biochemistry baseline values among T2DM and control subjects. The clinical biochemistry values among T2DM for vitamin $\mathrm{D}(\mathrm{P}<0.001)$, calcium $(\mathrm{P}<$ $0.001)$, magnesium ( $\mathrm{P}<0.001)$, potassium $(\mathrm{P}=0.012)$, phosphorous $(\mathrm{P}<0.001)$, fasting blood glucose $(\mathrm{P}<0.001)$, cholesterol $(\mathrm{P}<0.001), \mathrm{HbA1c}(\mathrm{P}<0.001)$, HLDL $(\mathrm{P}<0.001)$, LDL $(\mathrm{P}=0.021)$, albumin $(\mathrm{P}<0.001)$, triglyceride $(\mathrm{P}=0.005), \mathrm{SBP}$ $(\mathrm{mm} \mathrm{Hg})(\mathrm{P}<0.001)$ and diastolic blood pressure $(\mathrm{DBP})(\mathrm{P}<$ $0.001)$, TSH $(\mathrm{P}<0.001)$, T3 $(\mathrm{P}<0.001)$, and T4 $(\mathrm{P}<0.001)$ were lower than control subjects and statistically significant differences $(\mathrm{P}<0.001)$.

Table 3 gives clinical biochemistry baseline based on vi- 
Table 1. Socio-Demographic and Clinical Characteristics of Studied T2DM Patients and Control Subjects $(\mathrm{N}=1,092)$

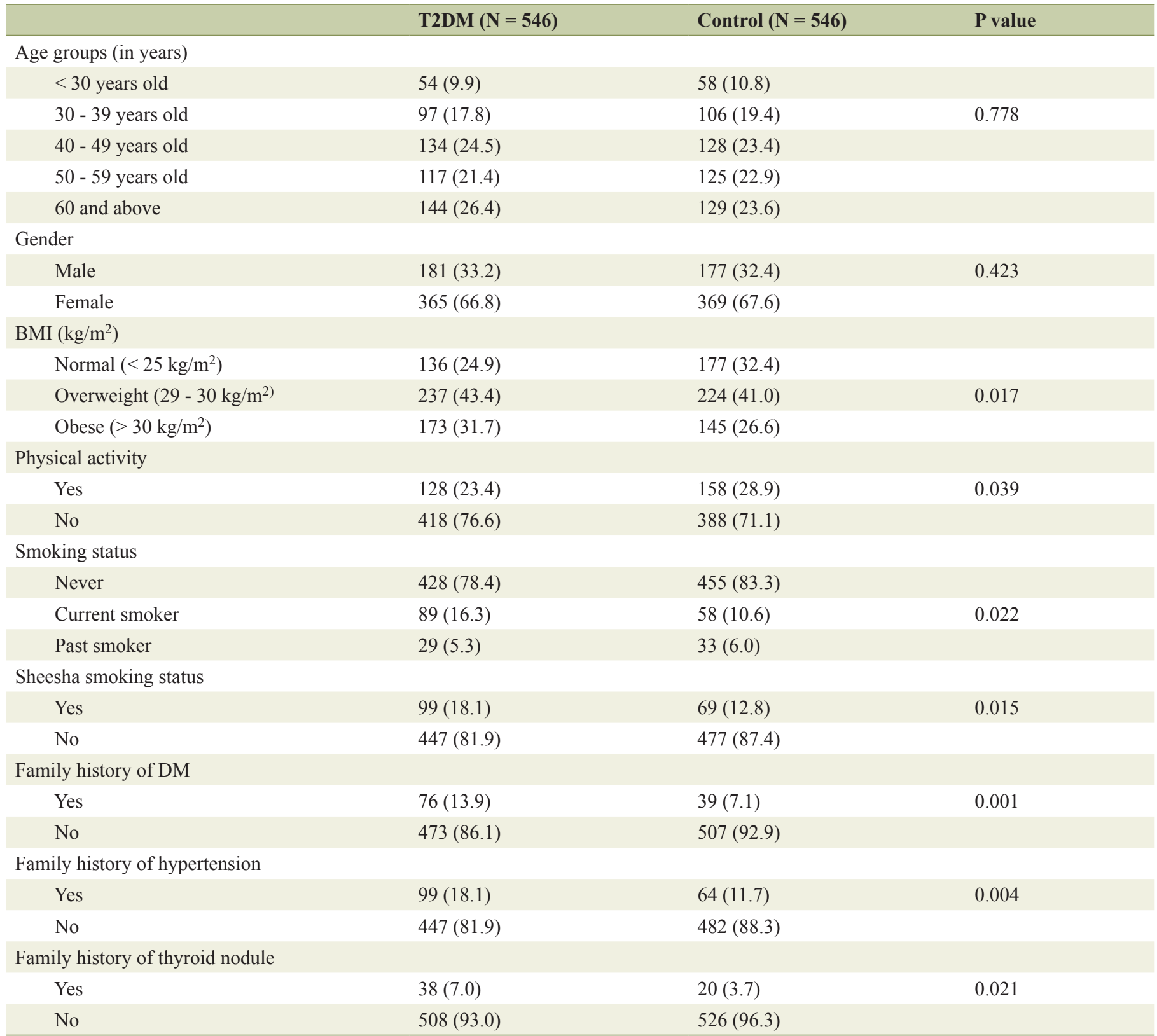

tamin D deficiency and sufficiency with and without thyroid nodules among T2DM and control subject. There were statistically significant differences between subjects vitamin D deficiency and sufficiency with and those without thyroid nodules for vitamin $\mathrm{D}(\mathrm{P}<0.001)$, calcium $(\mathrm{P}<0.001)$, magnesium $(\mathrm{P}$ $<0.001)$, phosphorous $(\mathrm{P}<0.001)$, HbAlc $(\mathrm{P}<0.001)$, HDL $(\mathrm{P}<0.001)$, SBP $(\mathrm{P}=0.006)$ and, DBP $(\mathrm{P}=0.005), \mathrm{TSH}(\mathrm{P}<$ $0.001)$, T3 $(\mathrm{P}<0.001)$, and T4 $(\mathrm{P}<0.001)$ among T2DM. Similarly, there were statistically significant differences between subjects vitamin D deficiency and sufficiency among control subjects for vitamin $\mathrm{D}(\mathrm{P}<0.001)$, calcium $(\mathrm{P}=0.002)$, magnesium $(\mathrm{P}<0.001)$, HbA1c $(\mathrm{P}<0.001)$, FBG $(\mathrm{P}<0.001)$, HDL $(\mathrm{P}<0.001)$, bilirubin $(\mathrm{P}=0.003)$ and, $\mathrm{DBP}(\mathrm{P}=0.027)$,
TSH $(\mathrm{P}<0.001)$, T3 $(\mathrm{P}<0.001)$, and T4 $(\mathrm{P}=0.002)$.

Table 4 presents clinical biochemistry baseline based on vitamin $\mathrm{D}$ deficiency level and with thyroid nodules among T2DM and control subject. There were statistically significant differences between both groups for vitamin $\mathrm{D}(\mathrm{P}<0.001)$, potassium $(\mathrm{P}=0.011)$, calcium $(\mathrm{P}<0.001)$, phosphorous $(\mathrm{P}<$ $0.001)$, fasting blood glucose $(\mathrm{P}<0.001)$, HbA1c $(\mathrm{P}<0.001)$, HDL $(\mathrm{P}=0.034)$, LDL $(\mathrm{P}<0.001)$, albumin $(\mathrm{P}<0.001)$, triglyceride $(\mathrm{P}=0.008)$, uric acid $(\mathrm{P}<0.001), \mathrm{SBP}(\mathrm{P}=0.006)$ and DBP $(\mathrm{P}<0.001)$, TSH $(\mathrm{P}<0.001), \mathrm{T} 3(\mathrm{P}=0.010)$, and T4 $(\mathrm{P}<0.001)$.

Table 5 gives multivariable stepwise logistic regression analysis of independent predictors for the presence of thy- 
Table 2. Clinical Biochemistry Baseline Value Among T2DM and Control Subjects $(\mathrm{N}=1,092)$

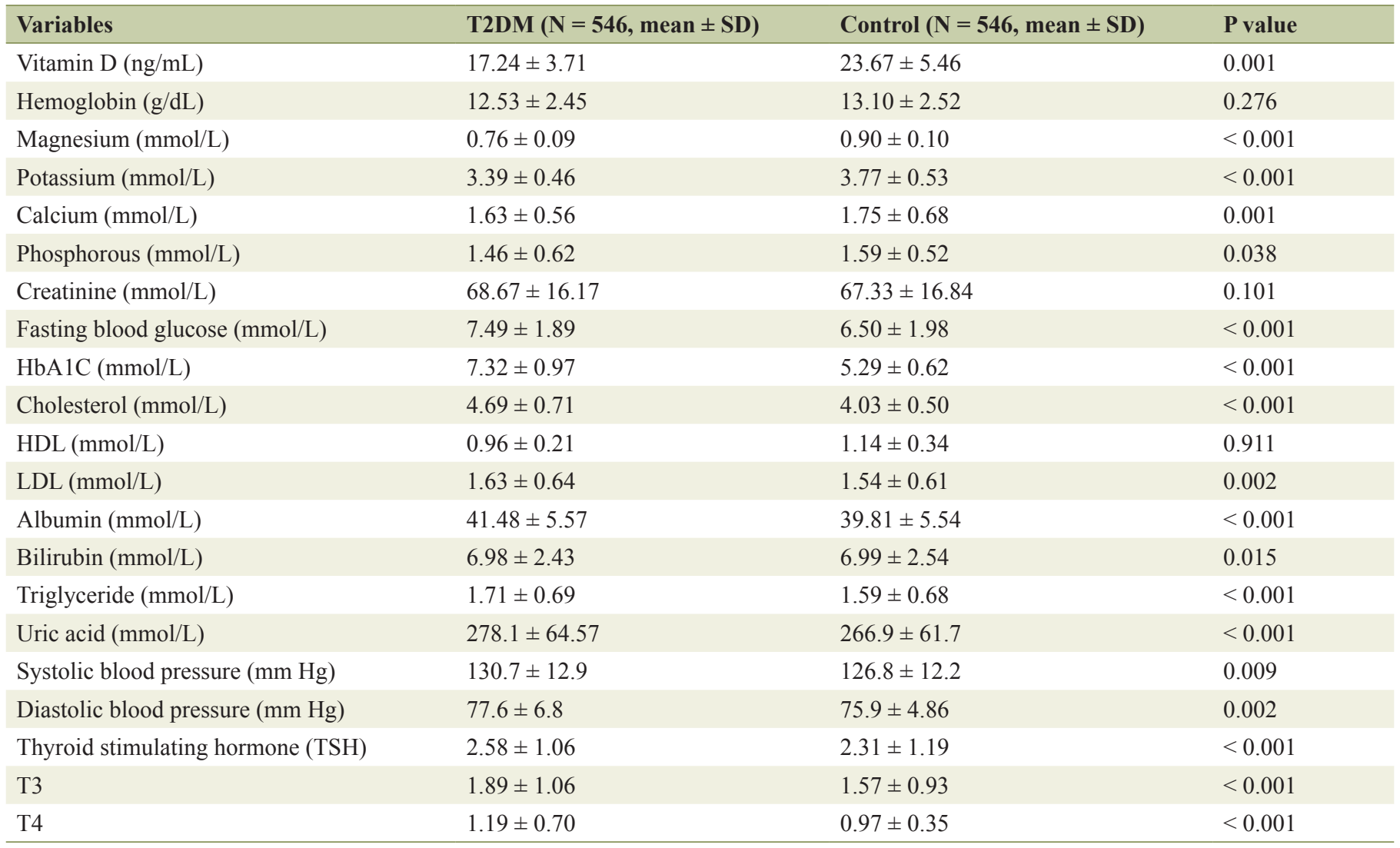

TSH (reference range: 0.35 - $4.0 \mathrm{mIU} / \mathrm{L}$ ), free triiodothyronine (FT3) (reference range: $1.71-4.71 \mathrm{pg} / \mathrm{mL}$ ), and free thyroxine (FT4) (reference range: $0.8-1.9 \mathrm{ng} / \mathrm{dL})$.

roid nodules. TSH mIU/L (OR: 4.41, 95\% CI: $3.22-5.61, \mathrm{P}<$ 0.001), HbA1c (OR: 3.67, 95\% CI: 2.84 - 4.92, P < 0.001), vitamin D deficiency (OR: 3.34 95\% CI: 1.60 - 5.50, P<0.001), SBP (mm Hg) (OR: 2.70, 95\% CI: 2.39 - 3.10, P < 0.001), family history of T2DM (OR: 2.41, 95\% CI: $2.13-3.87, \mathrm{P}<$ 0.001), BMI (OR: 2.23, 95\% CI: 1.94 - 3.06, $\mathrm{P}=0.005)$, serum calcium level $(\mathrm{mmol} / \mathrm{L})(\mathrm{P}=0.008)$, and family history of thyroid $(\mathrm{P}=0.010)$ were considered at higher risk as predictors of thyroid among T2DM patients.

\section{Discussion}

There are very few studies which determine the relationship between vitamin D deficiency and thyroid diseases among T2DM with thyroid diseases patients and controls subject as a worldwide. Our study has revealed a higher prevalence vitamin D deficiency with thyroid diseases in T2DM patients compared to control subjects. It has been recognized that vitamin D deficiency is a global major public health problem worldwide. In the current study, we conducted a matched case-control study to explore the relationship between vitamin D and thyroid disease among T2DM patients. Vitamin D deficiency has been correlated with thyroid antibody levels in both adult [18, 19] and children populations [20]. This is consistent with cur- rent study outcome.

Also, vitamin D deficiency and T2DM are usually recognized as a complication and risk for thyroid disease. Therefore, effective controls of vitamin D and T2DM are essential to reduce the occurrence of thyroid diseases in the middle age group and may affect the quality of life. Further, the current subjects with T2DM also had a higher prevalence and larger thyroid nodules size which is consistent with a previous reported a positive correlation between insulin resistance and thyroid nodule size [4-10]. The present study demonstrated very low mean vitamin D level deficiency with thyroid nodule compared to vitamin D sufficiency without thyroid nodule. This is confirmative with the previous reported studies $[11,12$, $18,19]$.

In fact, T2DM and thyroid diseases [5-9] are highly correlated as the two commonest endocrinological medical conditions reported and linked with the vitamin D deficiency in general clinical practice [10-15]. Further, several studies reported that thyroid volume is related to a variety of risk factors such as iodine deficiency and supply, BMI, age, gender, smoking status, genetic factors, impaired fasting glucose and diabetes mellitus [3, 19-21]. Additionally, a study has investigated the role of environmental and lifestyle factors [3]. It is worth to note that the possible role of vitamin D insufficiency/ deficiency can be considered in the pathogenesis of both DM 
Table 3. Clinical Biochemistry Baseline Based on Vitamin D Deficiency and Sufficiency With and Without Thyroid Nodules Among T2DM and Control Subject $(\mathrm{N}=1,092)$

\begin{tabular}{|c|c|c|c|c|c|c|}
\hline \multirow[b]{2}{*}{ Biochemistry indicators } & \multicolumn{3}{|c|}{ T2DM patients $(\mathrm{N}=546)$} & \multicolumn{3}{|c|}{ Control subjects $(\mathrm{N}=546)$} \\
\hline & $\begin{array}{l}\text { *Vitamin D defi- } \\
\text { ciency with thy- } \\
\text { roid nodule }(N= \\
186, \text { mean } \pm S D)\end{array}$ & $\begin{array}{l}* * \text { Vitamin D suf- } \\
\text { ficiency without } \\
\text { thyroid nodule }(\mathrm{N} \\
=360, \text { mean } \pm \mathrm{SD})\end{array}$ & P value & $\begin{array}{l}\text { *Vitamin D defi- } \\
\text { ciency with thy- } \\
\text { roid nodule }(\mathrm{N}= \\
178, \text { mean } \pm \mathrm{SD})\end{array}$ & $\begin{array}{l}* * \text { Vitamin D suf- } \\
\text { ficiency without } \\
\text { thyroid nodule }(\mathrm{N} \\
=368, \text { mean } \pm \text { SD) }\end{array}$ & P value \\
\hline Vitamin D (ng/mL) & $17.05 \pm 3.71$ & $21.76 \pm 4.96$ & 0.001 & $22.22 \pm 8.60$ & $25.43 \pm 9.07$ & $<0.001$ \\
\hline Hemoglobin (g/dL) & $12.76 \pm 2.35$ & $13.09 \pm 2.48$ & 0.248 & $12.90 \pm 2.48$ & $13.10 \pm 2.56$ & 0.275 \\
\hline Potassium (mmol/L) & $3.23 \pm 0.38$ & $3.47 \pm 0.49$ & 0.001 & $3.34 \pm 0.44$ & $3.58 \pm 0.60$ & $<0.001$ \\
\hline Serum calcium level (mmol/L) & $1.51 \pm 0.46$ & $1.70 \pm 0.60$ & $<0.001$ & $1.66 \pm 0.45$ & $1.84 \pm 0.84$ & 0.002 \\
\hline Phosphorous (mmol/L) & $1.25 \pm 0.29$ & $1.58 \pm 0.71$ & 0.001 & $1.58 \pm 0.49$ & $1.60 \pm 0.99$ & 0.983 \\
\hline Creatinine $(\mathrm{mmol} / \mathrm{L})$ & $68.2 \pm 16.4$ & $68.1 \pm 16.7$ & 0.642 & $68.3 \pm 16.2$ & $67.2 \pm 17.5$ & 0.492 \\
\hline Fasting blood glucose (mmol/L) & $7.60 \pm 1.72$ & $7.43 \pm 1.96$ & 0.351 & $6.11 \pm 1.35$ & $6.88 \pm 2.37$ & $<0.001$ \\
\hline LDL (mmol/L) & $1.92 \pm 0.63$ & $1.54 \pm 0.65$ & 0.045 & $1.67 \pm 0.66$ & $1.41 \pm 0.60$ & $<0.001$ \\
\hline Albumin (mmol/L) & $41.50 \pm 2.45$ & $40.75 \pm 3.92$ & 0.386 & $39.81 \pm 6.08$ & $40.75 \pm 3.92$ & 0.470 \\
\hline Bilirubin $(\mathrm{mmol} / \mathrm{L})$ & $6.39 \pm 2.43$ & $7.28 \pm 2.38$ & 0.253 & $6.66 \pm 2.47$ & $7.31 \pm 2.58$ & 0.003 \\
\hline Triglyceride (mmol/L) & $1.82 \pm 0.60$ & $1.50 \pm 0.72$ & 0.036 & $1.65 \pm 0.63$ & $1.154 \pm 0.71$ & 0.083 \\
\hline Uric acid $(\mathrm{mmol} / \mathrm{L})$ & $299.5 \pm 61.46$ & $280.1 \pm 64.85$ & $<0.001$ & $269.0 \pm 60.50$ & $264.9 \pm 62.90$ & 0.444 \\
\hline Systolic blood pressure (mm Hg) & $134.6 \pm 13.0$ & $131.31 \pm 13.6$ & 0.006 & $127.6 \pm 13.4$ & $126.2 \pm 130.76$ & 0.139 \\
\hline Diastolic blood pressure ( $\mathrm{mm} \mathrm{Hg}$ ) & $78.9 \pm 6.60$ & $77.2 \pm 6.7$ & $<0.001$ & $76.5 \pm 4.41$ & $75.5 \pm 5.21$ & 0.027 \\
\hline Thyroid stimulating hormone (TSH) & $2.75 \pm 0.95$ & $2.40 \pm 1.05$ & 0.005 & $1.97 \pm 1.26$ & $2.65 \pm 1.02$ & $<0.001$ \\
\hline
\end{tabular}

*Vitamin D deficiency: 25(OH)D level < $20 \mathrm{ng} / \mathrm{mL}$; **Vitamin D sufficiency: 25(OH) D level > $20 \mathrm{ng} / \mathrm{mL}$.

and thyroid disease. However, vitamin D deficiency could be also secondary to these diseases. Oral anti-diabetic medications as well as therapeutic dietary restriction could affect vitamin D levels in patients with diabetes. In addition, thyroid dysfunction could also modify vitamin D intake, absorption or metabolism.

In a few recent studies, thyroid cancer risk factors including iodine deficiency, environmental, genetic, family history of DM and hypertension and lifestyle factors [19-22]. Since the complex interplay between vitamin D and thyroid autoimmunity in the context of T2DM has been investigated more recently [22], this confirmative with the present study hypothesis could be substantiated on the basis of our data results. Thyroid cancer incidence has been raising very rapidly over time than the occurrence of cancers of other sites, due to increase of obesity, diabetes and lack of physical activity leading to increase risk of thyroid cancer [23-25]. Our results were similar to previous studies particularly that vitamin D deficiency was associated with an increased risk of thyroid disease among T2DM [19, 22, 26].

Furthermore, increased thyroid cancer risk in diabetics might be related to several factors including, abnormal HbA1C and metabolic syndrome, triglyceride levels, obesity, dietary, and lifestyle [7]. Obese subjects were at 10 times more risk of developing diabetes [23], and obesity was associated with an increased risk of thyroid cancer [25]. Our sample demonstrated significant prevalence of thyroid diseases among T2DM compared to controls. Finally, this study confirms previous reported studies $[18,19]$ to determine the correlations between vitamin D deficiency and thyroid diseases in diabetic patients in Turkish population and also indicates T2DM patients whose prevalence is very poorly described in earlier studies $[11,18]$.

\section{Limitations and strengths of study}

The study has several strengths, but also some weaknesses. The present study has several limitations. Firstly, the sample might be partially biased which may not be ideal for a matched case and control study. This is due to the possibility of selection bias as subjects were selected from patients who visited a tertiary hospital. Another limitation pertains to the unavail- 
Table 4. Clinical Biochemistry Baseline Based on Vitamin D Deficiency With Thyroid Nodules Among T2DM and Compared to Control Subject $(\mathrm{N}=364)$

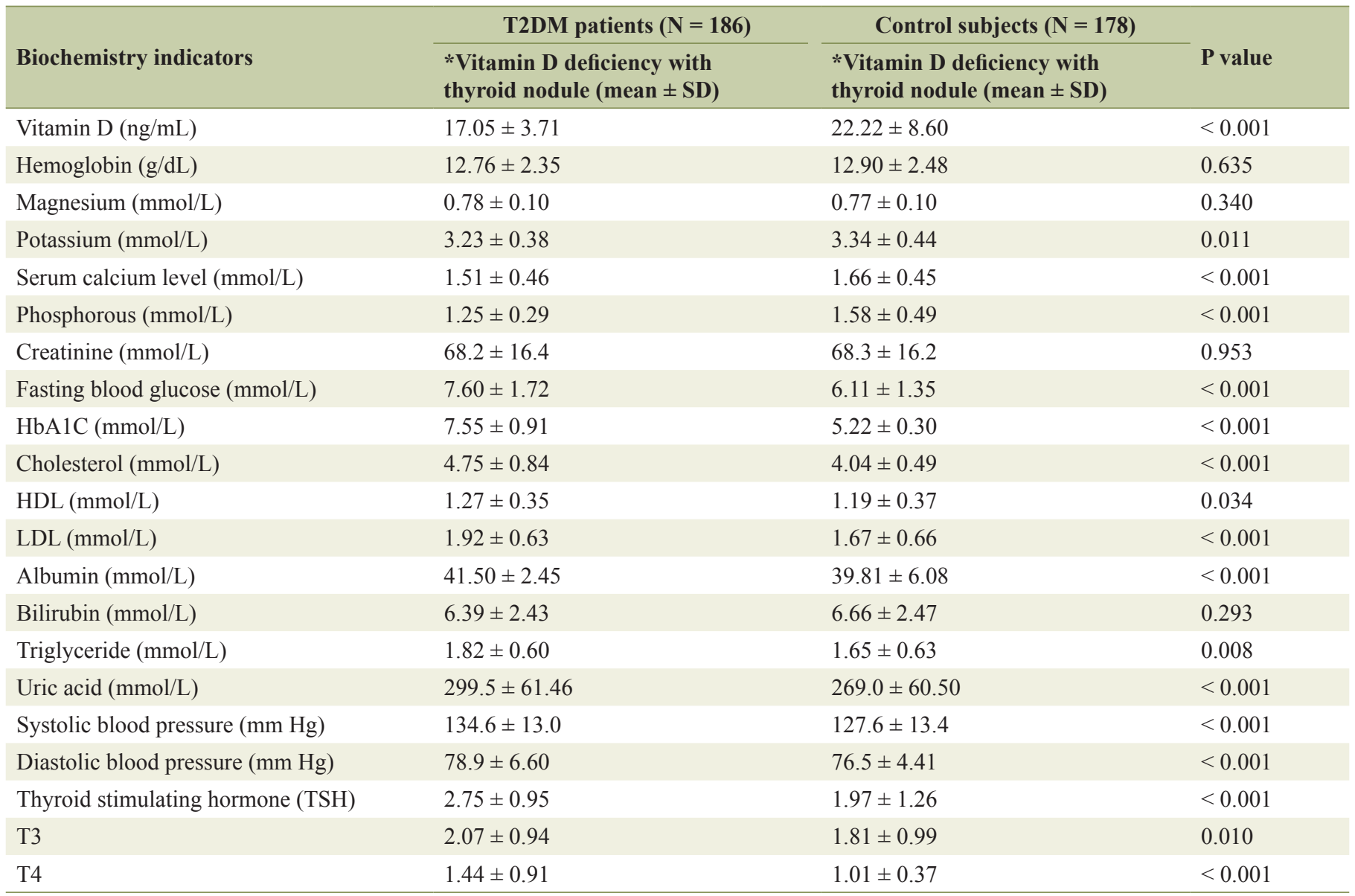

*Vitamin D deficiency: 25(OH)D level $<20 \mathrm{ng} / \mathrm{mL}$.

ability of data on the frequency of thyroid examinations in our study population. Lastly, there was no cytological or histological results for each nodule. The greatest strengths of this study are the very large sample of participants and the large dataset of risk factor variables such as TSH, T3, T4, body weight, physical activity, smoking cigarette, diet, BMI, family history of diabetes, hypertension and thyroid. Furthermore, the discrimination between the T2DM subjects and the control group was based on fasting blood glucose and HbAlc measurements, which secured a clear distinction between both groups.

\section{Conclusions}

This study suggests that obesity, HbAlc, the environment, and genetic susceptibility among T2DM may increase the risk of

Table 5. Multivariate Logistic Regression Analysis for Predictors Presence of Thyroid Disorder Among T2DM Patients $(\mathrm{N}=1,092)$

\begin{tabular}{llll}
\hline Independent variables & Adjusted odds ratio & $\mathbf{9 5 \%}$ Confidence interval & P value \\
\hline TSH, mIU/L & 4.41 & $3.22-5.61$ & $<0.001$ \\
HbA1C (mmol/L) & 3.67 & $2.84-4.92$ & $<0.001$ \\
Vitamin D deficiency & 3.34 & $1.60-5.50$ & $<0.001$ \\
Systolic blood pressure, mm Hg & 2.7 & $2.39-3.10$ & $<0.001$ \\
Family history of T2DM & 2.41 & $2.13-3.87$ & $<0.001$ \\
BMI $\left(\mathrm{kg} / \mathrm{m}^{2}\right)$ & 2.23 & $1.94-3.06$ & 0.005 \\
Serum calcium level (mmol/L) & 1.98 & $1.66-2.84$ & 0.008 \\
Family history of thyroid & 1.75 & $1.43-2.92$ & 0.01 \\
\hline
\end{tabular}


thyroid disease and cancer. There is a strong positive associations between the vitamin $\mathrm{D}$ deficiency and thyroid diseases population among T2DM patients. This study reveals that an increase in thyroid diseases might be caused by increases in metabolic syndrome, vitamin D deficiency, HbA1C, diabetes and obesity. Although evidence has shown that thyroid cancer incidence has been rising more rapidly over time than the occurrence of cancers of other sites due to an increase of obesity, diabetes and lack of physical activity, this study lacks of direct evidence supporting this conclusion.

\section{Acknowledgments}

This work was generously supported and funded by the Qatar Diabetes Association, Qatar Foundation. The authors would like to thank the Istanbul Medipol University for their support and ethical approval (Research Protocol and IRB\# 10840098604.01.01-E.8421).

\section{Author Contributions}

$\mathrm{AB}, \mathrm{MO}$ and $\mathrm{YO}$ designed and supervised the study and were involved in data collection, statistical analysis and the writing of the paper. AOAA, CCB were involved in study designed, interpretation of data and writing of the manuscript. All authors approved the final version.

\section{Conflict of Interest}

No conflict of interest was declared by the authors.

\section{Financial Support}

The authors declared that this study has received no financial support.

\section{References}

1. Alberti KG, Eckel RH, Grundy SM, Zimmet PZ, Cleeman JI, Donato KA, Fruchart JC, et al. Harmonizing the metabolic syndrome: a joint interim statement of the International Diabetes Federation Task Force on Epidemiology and Prevention; National Heart, Lung, and Blood Institute; American Heart Association; World Heart Federation; International Atherosclerosis Society; and International Association for the Study of Obesity. Circulation. 2009;120(16):1640-1645.

2. Bener A, Zirie M, Musallam M, Khader YS, Al-Hamaq AO. Prevalence of metabolic syndrome according to Adult Treatment Panel III and International Diabetes Federation criteria: a population-based study. Metab Syndr Relat Disord. 2009;7(3):221-229.

3. Bener A, Al-Hamaq AO, Kurtulus EM, Abdullatef WK,
Zirie M. The role of vitamin D, obesity and physical exercise in regulation of glycemia in Type 2 Diabetes Mellitus patients. Diabetes Metab Syndr. 2016;10(4):198-204.

4. Al-Wazzan HT, Daban AH, Askar RA. El-Shazly MK. Prevalence and associated factors of thyroid dysfunction among type 2 diabetic patients in Kuwait. Alex Bull. 2010;46(2):141-148.

5. Papazafiropoulou A, Sotiropoulos A, Kokolaki A, Kardara M, Stamataki P, Pappas S. Prevalence of thyroid dysfunction among greek type 2 diabetic patients attending an outpatient clinic. J Clin Med Res. 2010;2(2):75-78.

6. Akbar DH, Ahmed MM, Al-Mughales J. Thyroid dysfunction and thyroid autoimmunity in Saudi type 2 diabetics. Acta Diabetol. 2006;43(1):14-18.

7. Bener A, Ozdenkaya Y, Barişik CC, Ozturk M. The impact of metabolic syndrome on increased risk of thyroid nodules and size. Health Service Res Man Epidemiology. 2018;5:1-6.

8. Sarfo-Kantanka O, Sarfo FS, Ansah EO, Yorke E, Akpalu J, Nkum BC, Eghan B. Frequency and determinants of thyroid autoimmunity in Ghanaian type 2 diabetes patients: a case-control study. BMC Endocr Disord. 2017;17(1):2.

9. Centeno Maxzud M, Gomez Rasjido L, Fregenal M, Arias Calafiore F, Cordoba Lanus M, D'Urso M, Luciardi H. [Prevalence of thyroid dysfunction in patients with type 2 diabetes mellitus]. Medicina (B Aires). 2016;76(6):355358.

10. Van Belle TL, Gysemans C, Mathieu C. Vitamin D and diabetes: the odd couple. Trends Endocrinol Metab. 2013;24(11):561-568.

11. Bozkurt NC, Karbek B, Ucan B, Sahin M, Cakal E, Ozbek M, Delibasi T. The association between severity of vitamin D deficiency and Hashimoto's thyroiditis. Endocr Pract. 2013;19(3):479-484.

12. Kim D. Low vitamin D status is associated with hypothyroid Hashimoto's thyroiditis. Hormones (Athens). 2016;15(3):385-393.

13. Kivity S, Agmon-Levin N, Zisappl M, Shapira Y, Nagy EV, Danko K, Szekanecz Z, et al. Vitamin D and autoimmune thyroid diseases. Cell Mol Immunol. 2011;8(3):243247.

14. Mazokopakis EE, Kotsiris DA. Hashimoto's autoimmune thyroiditis and vitamin D deficiency. Current aspects. Hell J Nucl Med. 2014;17(1):37-40.

15. Holick MF. Vitamin D deficiency. N Engl J Med. 2007;357(3):266-281.

16. Brunn J, Block U, Ruf G, Bos I, Kunze WP, Scriba PC. [Volumetric analysis of thyroid lobes by real-time ultrasound (author's transl)]. Dtsch Med Wochenschr. 1981;106(41):1338-1340.

17. Gharib H, Tuttle RM, Baskin HJ, Fish LH, Singer PA, McDermott MT. Subclinical thyroid dysfunction: a joint statement on management from the American Association of Clinical Endocrinologists, the American Thyroid Association, and the Endocrine Society. J Clin Endocrinol Metab. 2005;90(1):581-585; discussion 586-587.

18. Camurdan OM, Doger E, Bideci A, Celik N, Cinaz P. Vitamin D status in children with Hashimoto thyroiditis. 
J Pediatr Endocrinol Metab. 2012;25(5-6):467-470.

19. Shin DY, Kim KJ, Kim D, Hwang S, Lee EJ. Low serum vitamin $\mathrm{D}$ is associated with anti-thyroid peroxidase antibody in autoimmune thyroiditis. Yonsei Med J. 2014;55(2):476-481.

20. Welsh KJ, Soldin SJ. Diagnosis of endocrine disease: How reliable are free thyroid and total T3 hormone assays? Eur J Endocrinol. 2016;175(6):R255-R263.

21. Palma CC, Pavesi M, Nogueira VG, Clemente EL, Vasconcellos Mde F, Pereira LCJ, Pacheco FF, et al. Prevalence of thyroid dysfunction in patients with diabetes mellitus. Diabetol Metab Syndr. 2013;5(1):58.

22. Toulis K, Tsekmekidou X, Potolidis E, Didangelos T, Gotzamani-Psarrakou A, Zebekakis P, Daniilidis M, et al. Thyroid autoimmunity in the context of type 2 diabetes mellitus: implications for Vitamin D. Int J Endocrinol. 2015;2015:710363.
23. Aschebrook-Kilfoy B, Sabra MM, Brenner A, Moore SC, Ron E, Schatzkin A, Hollenbeck A, et al. Diabetes and thyroid cancer risk in the National Institutes of HealthAARP Diet and Health Study. Thyroid. 2011;21(9):957963.

24. Schmid D, Behrens G, Jochem C, Keimling M, Leitzmann M. Physical activity, diabetes, and risk of thyroid cancer: a systematic review and meta-analysis. Eur J Epidemiol. 2013;28(12):945-958.

25. Leitzmann MF, Brenner A, Moore SC, Koebnick C, Park Y, Hollenbeck A, Schatzkin A, et al. Prospective study of body mass index, physical activity and thyroid cancer. Int J Cancer. 2010;126(12):2947-2956.

26. D'Aurizio F, Villalta D, Metus P, Doretto P, Tozzoli R. Is vitamin D a player or not in the pathophysiology of autoimmune thyroid diseases? Autoimmun Rev. 2015;14(5):363-369. 